J. Lake Sci. (湖泊科学) , 2011, 23(4):635-641

http: //www. jlakes. org. E-mail : jlakes@niglas.ac.cn

(C) 2011 by Journal of Lake Sciences

\title{
淮河具有行蓄洪区河系洪水预报水力学模型研究"
}

\author{
包红军 ${ }^{1,2}$, 赵琳娜 ${ }^{1,2}$, 李致家 ${ }^{3}$ \\ (1: 中国气象局公共气象服务中心, 北京 100081) \\ ( 2 : 国家气象中心, 中国气象局, 北京 100081) \\ $(3$ : 河海大学水文水资源学院, 南京 210098$)$
}

摘 要: 针对淮河流域河系特点,建立淮河具有行蓄洪区河系洪水预报模型. 干流河道洪水演进采用一维水动力学模型, 钐岗分流量利用分流曲线法推求,利用虚拟线性水库法解决大洪水时支流洪水受干流顶托作用,临淮岗闸作为水力学模 型的内边界条件进行处理, 利用分流比法概化行洪过程, 行洪区内只有蓄满时,才会有出流,行洪区内的洪水利用 Muskingum 法进行洪水演进; 由于蓄洪区进洪与出流均有闸门控制, 因而作为水库处理, 蓄洪区内不考虑洪水演进, 只进行水量 平衡以判断进洪或者出流. 以淮河干流王家坝至鲁台子河系为例, 建立淮河具有行蓄洪区河系水力学模型, 并与淮河具 有行蓄洪区河系水文学模型在淮河 2003-2008 年洪水进行对比验证检验. 结果表明,所建立的淮河具有行蓄洪区河系洪 水预报水力学模型在淮河洪检验取得较好的预报效果,也证明了所建模型的合理性.

关键词 : 洪水预报;分流比法;一维水动力学模型; Muskingum 法;行蓄洪;淮河

\section{Hydraulic model for flood forecast of river basin with flood diversion and flood retarding areas of Huaihe River}

\author{
BAO Hongjun ${ }^{1,2}$, ZHAO Linna ${ }^{1,2} \&$ LI Zhijia ${ }^{3}$ \\ (1: Public Meteorological Service Center, China Meteorological Administration, Beijing 100081, P. R. China) \\ (2: National Meteorological Center, China Meteorological Administration, Beijing 100081, P. R. China) \\ (3: College of Hydrology and Water Resources, Hohai University, Nanjing 210098, P. R. China)
}

Abstract: Hydraulic model of Huaihe River with flood diversion and flood retarding areas was developed for flood forecast. The input flood discharge hydrograph from the main channel to the flood diversion area is estimated with the fixed split ratio of the main channel discharge. The Muskingum discharge routing method is applied in the flood diversion area, and outflow can generate only after it reaches full storage. The flood flow inside the flood retarding area is calculated as a reservoir and inflow and outflow are calculated based on the water balance equation. Taking complex river basin between Wangjiaba and Lutaizi stations with flood diversion and flood retarding areas of Huaihe River as an example, with taking the Linhuaigang Project as inside boundary in flood routing, Hydraulic model of Huaihe River based on one-dimension hydraulic model was developed. In order to testify the performance and rationality of the developed model, the representative flood events from 2003 to 2008 were forecasted with the developed hydraulic model. Results show that the developed model performs well and is reasonable.

Keywords: Flood forecast; split ratio; one-dimension hydraulic model; Muskingum; flood diversion and flood retarding; Huaihe River

大流域内存在水库、蓄滞洪区、水闸等多种水利工程, 流域水文系统的降雨径流及洪水过程预报是一个 十分复杂的问题 ${ }^{[-5]}$. 大江大河的洪水预报一般是以干流河道的汇流为主线,防洪控制站大部分均设在干流 沿程河道. 而我国大江大河中下游一般是丘陵和平原区, 河底比较平缓, 不太适合建大型的水库, 防洪工程 主要堤防以及借助于两岸地理与地形条件修建的行蓄洪区, 其标准往往不高. 淮河流域就是这类典型具有

* 公益性行业(气象)科研专项项目(GYHY200906007,GYHY201006037)资助. 2010-05-20 收稿;2010-09-19 收 修改稿. 包红军,男,1980 年生,博士,工程师;E-mail : baohongjun@ cma. gov. cn. 
行蓄洪区的复杂大流域. 包红军等 ${ }^{[6]}$ 在考虑行蓄洪区影响的 Muskingum 流量演算法基础之上, 将 Muskingum 法与水文水位法、扩散波非线性水位法相结合建立淮河具有行蓄洪区河系洪水预报水文学模型, 在 2007 年 淮河洪水中取得良好的预报流量检验效果, 水位预报效果相对一般; 对于复杂的分叉水系的洪水预报, 需要 计算和预报河道内任何断面任何时刻的水位、流速、流量等要素, 这时水动力学方法是首选 ${ }^{[7]}$. 吴时强等 ${ }^{[8-9]}$ 采用淮河干流及各行洪区采用平面二维水动力学模型进行洪水演算, 在淮河 1982 年、1991 年大洪水预报中 得到不错的预报效果; 而在淮河大洪水行洪过程中, 行洪区口门往往通过爆破方式炸开, 口门在行洪过程中 不断扩大变深, 口门尺寸的变化难于计算 ${ }^{[3]}$; 行洪区内二维河道资料变化也由于历史人工影响, 较难获取; 因此本文基于一维水动力学模型 ${ }^{[7,10-11]}$, 对行蓄洪区进行概化处理: 行洪区采用分流比概化处理行洪, 行洪 区只有蓄满时, 才会有出流, 行洪区内的洪水考虑洪水演进; 由于蓄洪区进洪出流均有闸门控制, 将蓄洪区 看成水库, 蓄洪区内不考虑洪水演进, 只进行水量平衡以判别是进洪或者出流, 建立淮河具有行蓄洪区河系 水力学模型, 合理处理好缷岗分流, 大洪水时支流洪水受干流顶托作用, 临淮岗闸对洪水演进的影响, 并与 淮河具有行蓄洪区河系水文学模型进行洪水预报对比研究.

\section{1 研究流域简介与概化}

淮河流域发源于河南省桐柏山, 在江苏省三江营注人长江, 干流全长 $1000 \mathrm{~km}$, 淮河流域分上、中、下游. 王家坝以上为上游, 汇水面积 $30630 \mathrm{~km}^{2}$; 王家坝至三河闸为中游, 河道坡降平缓, 沿干流两侧多湖泊洼地, 淮 河上中游洪水在此滞蓄回旋. 淮河上游自洪河口至洪泽湖汇水面积 $158160 \mathrm{~km}^{2}$. 王家坝至鲁台子属中游河 段, 鲁台子汇水面积 $91620 \mathrm{~km}^{2}$ (图 1). 淮河中游支流多、水量大量集中, 上游干支来水以王家坝居多, 以下汇 史、㴓、颖三大支流,至正阳关集中了淮河水量的 $80 \%$. 这段干流有三个行洪区,四个蓄洪区.

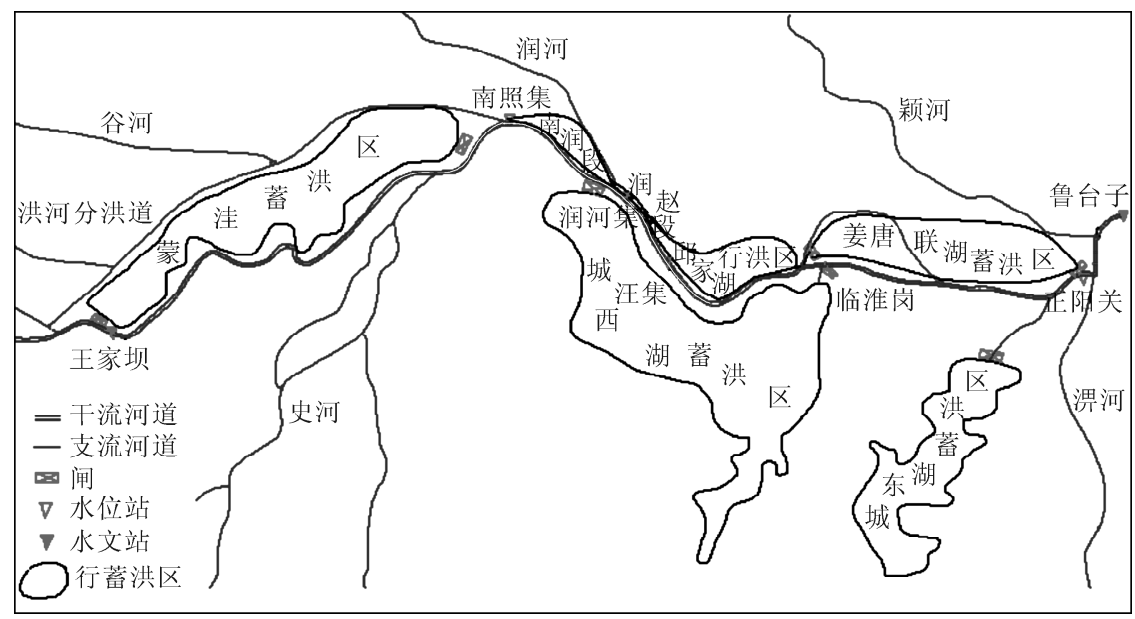

图 1 淮河王家坝至鲁台子河段概化图

Fig. 1 Sketch of the river basin from Wangjiaba to Lutaizi station of Huaihe River

\section{2 淮河具有行蓄洪区河系水力学预报模型的构建}

淮河具有行蓄洪区河系水力学模型, 考虑了行蓄洪区的洪水调度: 行洪区采用分流比和口门行洪两种 处理方式, 行洪区只有蓄满时, 才会有出流, 行洪区内的洪水考虑洪水演进; 由于蓄洪区进洪出流均有闸门 控制, 将蓄洪区看成水库, 蓄洪区内不考虑洪水演进, 只进行水量平衡以判别是进洪还是出流. 淮河具有行 蓄洪区河系水力学模型结构, 可以划分为四部分, 干流河道基于一维水动力学模型的水位流量预报; 行蓄洪 区的洪水演算预报;旁侧人流及无资料地区产汇流预报;临淮岗水利枢纽的考虑. 


\section{1 一维水动力学模型}

取水位 $Z$ 和流量 $Q$ 为水力要素, 水力学模型一维方程形式可写为:

水流连续方程:

$$
\partial A / \partial t+\partial Q / x=L_{q}
$$

水流运动方程:

$$
\frac{\partial Q}{\partial t}+\frac{\partial}{\partial x}\left(\frac{\alpha Q^{2}}{A}\right)+g A\left(\frac{\partial Z}{\partial x}+S_{f}\right)+L_{q} \frac{Q}{A}=0
$$

式中: $Z$ 为水位, $Q$ 为流量, $A$ 为过水断面面积, $L_{q}$ 为单位河长的旁侧人流, $x$ 为沿水流方向的水平距离, $t$ 为时 间, $g$ 为重力加速度, $\alpha$ 为流速分布不均匀系数, $S_{f}$ 为水力比降, $S_{f}=\left(n^{2} Q|Q|\right) /\left(A^{2} R^{4 / 3}\right)$. 采用 Preissmann 四 点线性隐式差分进行离散,应用 Newton-Raphson 迭代求解法进行水位流量计算.

\section{2 行蓄洪区洪水演算预报}

行洪区一般是利用河道边的地形, 比如洼地、湖泊,形成一个洪水期间的临时蓄水体或者过水通道. 为 了与蓄洪区区别开来, 本文研究的淮河流域行洪区进洪口与出洪口都没有闸门控制. 蓄洪区是分布在河道 两侧, 利用河道边的地形, 如洼地、湖泊, 形成一个有闸门控制进出流的临时蓄水体. 行洪区和蓄洪区的区别 在于蓄洪区的进洪与出洪口有控制闸门而行洪区则没有. 由于有闸门控制, 蓄洪区有一定的库容. 目前关于 行蓄洪区的处理方法国内外大致有以下 2 种:经验方法 (分流比法) 和固定口门水力学公式法. 文献 [3] 已经 证明了经验方法分流比法具有一定的物理意义, 简单易行, 可以用于洪水预报中. 因此, 本文采用分流比法 进行行洪处理. 分流比常用的确定途径有两个:由实测流量来确定和由口门特征来确定.

2.2.1 由实测流量来确定 行洪口的行洪流量是很难实测到的,一般是洪水过后, 根据行洪口门的大小由水 力学公式估算出来的特征值,如最大流量等. 行洪口的行洪流量与干流总量之比是分流比. 一般估算出来的

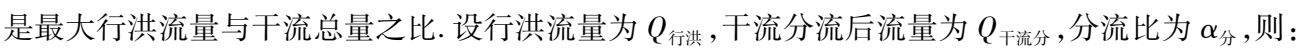

$$
\alpha_{\text {分 }}=Q_{\text {行洪 }} /\left(Q_{\text {行洪 }}+Q_{\text {干流分 }}\right)
$$

2.2.2 由口门特征来确定 由行洪区口门的特征与行洪流量建立关系, 行洪口门的特征主要是口门的宽度 与深度, 根据宽顶堰公式:

$$
Q_{\text {行洪 }}=B \times K_{1} \times \sqrt{2} g \times H U^{2 / 3}
$$

式中: $B$ 为口门宽度, $K_{1}$ 为流量系数, 其值在 $0.300-0.385$ 之间, $H U$ 为有效水头, 在这里取河道干流水位与 口门高程之差. 参数 $B 、 H U$ 均由口门尺寸和河道水位计算得出, $K_{1}$ 值需要进行水力学实验中率定, 在防洪计 算中一般取 $0.385^{[3]}$, 本文取 $K_{1}$ 为 0.385 . 用口门特征来确定分流比, 主要是由于没有行洪区的流量资料, 这 是可根据口门尺寸以及干流的记录的水位来定出流量的特征值, 以及定出分流比.

行洪区内的洪水演进, 由于缺乏地形资料, 本文采用 Muskingum 法进行演算.

蓄洪区的处理方式就是把蓄洪区看成一个进库出库均有闸门控制的水库. 蓄洪区进洪与出洪可由水力 学公式计算. 设干流水位为 $Z$, 蓄洪区水位为 $Z_{1}$, 闸底板高程为 $Z_{0}$, 令 $H_{0}=Z-Z_{0}, H_{\mathrm{s}}=Z_{1}-Z_{0}$, 当 $H_{0}>$ $1.33 H_{\mathrm{s}}$ 时为自由进洪, 进洪流量 $Q_{\mathrm{s}}=M_{1} \times B \times H_{0}{ }^{2 / 3}$. 当 $H_{0} \leqslant 1.33 H_{\mathrm{s}}$, 且 $Z-Z_{1}>0$ 时,

$$
Q_{\mathrm{s}}=M_{1} \times B \times H_{\mathrm{s}} \times \sqrt{Z-Z_{1}}
$$

式中: $M_{1}$ 为闸门进洪系数, 通过水力学实验获取 $M_{1}$ 与 $H_{\mathrm{s}} / H_{0}$ 的关系, 随水位变化推求参数 $M_{1}$ 值, 具体参见文 献 $[11], B$ 为闸门开启净宽度.

对于蓄洪区的出洪闸计算与进洪闸相似, 不同之处是 $Z$ 与 $Z_{1}$ 更换了位置. 对于蓄洪区内部, 不考虑洪水 演进问题, 只对蓄洪区内进行水量平衡计算求出蓄洪区水位变化以判别是否进洪或者出洪.

\section{3 旁侧入流及无资料地区产汇流计算}

王家坝处的分流问题:钐岗的分流量由王家坝与钐岗的分流关系曲线确定. 王家坝闸的分流量根据闸 门运行方式和水流的实际形态, 采用恰当的水力学公式计算. 把钐岗分流后与地理城的流量作为旁侧人流 
合在一起演算至干流. 此外中游支流蒋家集、阜阳和横排头也分别作为旁侧人流演算至干流. 为了解决大洪 水时支流洪水受干流顶托作用, 直至退水期才能进人干流, 故借鉴文献 [3] 的方法: 在支流末端与干流交汇 处设一虚拟线性水库,支流水流必须经过水库调蓄后才能进人干流.

蒋家集至干流汇合处,谷河、润河集以及皁阳、横排头至干流的区间面积有 $8730 \mathrm{~km}^{2}$, 占鲁台子的汇水面 积的 $8.7 \%$. 为了解决这部分地区的产汇流计算, 选淮北王市集小流域为代表性流域, 用新安江模型进行产 汇流计算, 然后将参数移置到区间上.

\section{4 临淮岗枢纽工程的考虑}

按照临淮岗控制工程的规划条件, 当正阳关水位达到 $26.40 \mathrm{~m}$ 、鲁台子流量达到 $10000 \mathrm{~m}^{3} / \mathrm{s}$ 时, 启用临淮 岗枢纽控泄. 本文按临淮岗闸门全关、敞泄、控泄三种方式讨论临淮岗闸在洪水预报中的处理方法.

2.4.1 临淮岗枢纽闸门全关当临淮岗枢纽闸门全关时,则淮河干流被截为两段. 在河道洪水预报时, 临淮 岗枢纽以上河段就可以看作为一个水库,进行水库调度;下游河道进行上边界为 0 的河道洪水预报.

2.4.2 临淮岗枢纽敞泄当临淮岗枢纽敞泄时, 将河道作为一个整体处理. 将临淮岗深孔闸与浅孔闸均作为 宽顶堰或者实用堰进行内边界处理. 堰流的基本计算公式为:

$$
Q=\sigma m n b \sqrt{2 g} H_{0}^{3 / 2}
$$

式中, $b$ 为每孔净宽 $(\mathrm{m}), n$ 为闸孔孔数, $H_{0}$ 为包括行近水头, $m$ 为自由堰流的流量系数, $\sigma$ 侧收缩系数. 令 $\mu$ $=\sigma m$, 为包括侧收缩系数在内的流量系数. 参数 $\mu$ 取值, 根据毛租熙 ${ }^{[12]}$ 拟合出流量模数的经验公式进行 计算:

$$
\mu=0.35 \sqrt{1-\left(\frac{0.3-H_{0} / L}{0.4}\right)}
$$

式中, $L$ 为闸地板长度, 当 $H_{0} / L>0.3$ 时, 仍用 0.3 代人.

2.4.3 临淮岗枢纽控泄当临淮岗枢纽实行控泄时, 仍然将临淮岗枢纽作为一个内边界处理. 此时临淮岗闸 为孔流泄流. 计算公式如下:

$$
Q=\sigma_{c} \mu_{0} n b e \sqrt{2 g H_{0}}
$$

式中, $n b$ 为闸门净宽 $(\mathrm{m}), e$ 为闸门开度 $(\mathrm{m}), \mu_{0}$ 为孔流流量系数, $\sigma_{c}$ 为淹没系数, 具体取值方法参见文献 [12],本文进行预报的洪水均为临淮岗闸敞泄状况下的.

\section{3 淮河具有行蓄洪区河系水力学模型的验证}

\section{1 淮河具有行蓄洪区河系水力学模型在淮河洪水中的对比检验}

钐岗分流量由王家坝与钐岗的分流关系曲线确定. 统计实测期 (1996-2004 年汛期) 内的资料, 得到一 个以王家坝总人流为横坐标、钐岗分流量为纵坐标的带状点群. 此点群的特点是: 在流量较小的时候, 点距 非常密集; 随着流量的增加, 点距逐渐稀疏, 但仍旧保持带状分布. 综合实测的数值及点群的特征, 结合已有 的经验,得到钐岗的分流公式.

对于淮河具有行蓄洪区河系水文学模型, 采用 Muskingum-Cunge 法进行干流王家坝至鲁台子河道洪水 演进,利用水文水位法进行鲁台子水位预报,最后采用扩散波非线性水位法推求河道各个断面水位预报过 程. 采用水力学模型相同的行蓄洪区处理方式、旁侧人流及无资料地区产汇流预报的方法.

采用 $1996-2004$ 年的 6 场汛期洪水进行水动力学模型的曼宁粘率参数进行率定, 率定得到的精率系数 在垂直方向分别为 $0.018 、 0.020 、 0.022 、 0.020$ 和 $0.020 、 0.022 、 0.025 、 0.022$. 率定期的水动力学的上边界为 王家坝干流的人流过程, 下边界为鲁台子的水位过程. 采用 2005-2008 年的汛期洪水进行检验, 并与淮河具 有行蓄洪区河系水文学模型的预报结果进行对比 (表 1), 结果表明, 水力学模型在淮河 $2005-2008$ 年的洪 水预报中取得良好的模拟结果: 润河集、鲁台子的流量平均洪峰误差分别为 $13.5 \% 、 16.3 \%$, 南照集、正阳关 的水位预报绝对误差分别 $0.24 、 0.25 \mathrm{~m}$, 确定性系数均大于 0.8 (表 1). 水力学模型的水位流量预报效果均 好于水文学模型: 其中流量预报水力学模型稍好一些, 润河集、鲁台子站的平均确定性系数为 $0.921 、 0.866$, 
而水文学模型预报的润河集、鲁台子站的平均确定性系数为 $0.889 、 0.759$. 水力学模型水位预报精度有较大 的提高: 南照集、正阳关的水位预报平均绝对误差分别为 $0.24 、 0.25 \mathrm{~m}$, 而水文学模型的南照集、正阳关水位 预报平均绝对误差分别为 $0.88 、 1.00 \mathrm{~m}$.

表 1 淮河具有行蓄洪区河系水力学模型和水文学模型检验期的预报结果

Tab. 1 Validation results of hydraulic model and hydrologic model with flood diversion and flood retarding areas of Huaihe River

\begin{tabular}{|c|c|c|c|c|c|c|c|c|c|}
\hline \multirow[b]{2}{*}{ 模型 } & \multirow[b]{2}{*}{ 洪号 } & \multicolumn{2}{|c|}{ 南照集 } & \multicolumn{2}{|c|}{ 润河集 } & \multicolumn{2}{|c|}{ 正阳关 } & \multicolumn{2}{|c|}{ 鲁台子 } \\
\hline & & $\begin{array}{l}\text { 水位绝对 } \\
\text { 误差 }(\mathrm{m})\end{array}$ & $\begin{array}{c}\text { 水位预报 } \\
\text { 确定性系数 }\end{array}$ & $\begin{array}{l}\text { 洪峰流量相 } \\
\text { 对误差 }(\%)\end{array}$ & $\begin{array}{c}\text { 流量预报 } \\
\text { 确定性系数 }\end{array}$ & $\begin{array}{l}\text { 水位绝对 } \\
\text { 误差 }(\mathrm{m})\end{array}$ & $\begin{array}{c}\text { 水位预报 } \\
\text { 确定性系数 }\end{array}$ & $\begin{array}{l}\text { 洪峰流量相 } \\
\text { 对误差(\%) }\end{array}$ & $\begin{array}{c}\text { 流量预报 } \\
\text { 确定性系数 }\end{array}$ \\
\hline \multirow[t]{7}{*}{ 水力学 } & 20050626 & 0.26 & 0.901 & -2.1 & 0.935 & -0.30 & 0.863 & 3.1 & 0.965 \\
\hline & 20050821 & 0.18 & 0.881 & -27.6 & 0.929 & -0.30 & 0.836 & -25.1 & 0.841 \\
\hline & 20060624 & 0.19 & 0.881 & 11.2 & 0.878 & -0.17 & 0.913 & 13.7 & 0.863 \\
\hline & 20060721 & -0.33 & 0.864 & -6.6 & 0.915 & -0.25 & 0.901 & -9.8 & 0.894 \\
\hline & 20080704 & -0.21 & 0.881 & -21.7 & 0.907 & -0.23 & 0.903 & -28.2 & 0.807 \\
\hline & 20080813 & -0.26 & 0.853 & -12.1 & 0.964 & -0.29 & 0.898 & -18.3 & 0.827 \\
\hline & 绝对值平均 & 0.24 & 0.877 & 13.5 & 0.921 & 0.25 & 0.886 & 16.3 & 0.866 \\
\hline \multirow[t]{7}{*}{ 水文学 } & 20050626 & -0.32 & 0.822 & 5.2 & 0.904 & 0.33 & 0.832 & -9.3 & 0.818 \\
\hline & 20050821 & -0.68 & 0.726 & 30.6 & 0.895 & 0.29 & 0.821 & 16.3 & 0.813 \\
\hline & 20060624 & -1.05 & 0.642 & -13.1 & 0.882 & -1.29 & 0.615 & -18.9 & 0.829 \\
\hline & 20060721 & -1.48 & 0.535 & 14.3 & 0.862 & -1.49 & 0.382 & -34.3 & 0.444 \\
\hline & 20080704 & -0.95 & 0.734 & 17.1 & 0.901 & -1.51 & 0.432 & 8.2 & 0.913 \\
\hline & 20080813 & -0.79 & 0.711 & 18.9 & 0.887 & -1.09 & 0.673 & 17.8 & 0.737 \\
\hline & 绝对值平均 & 0.88 & 0.695 & 16.5 & 0.889 & 1.00 & 0.626 & 17.5 & 0.759 \\
\hline
\end{tabular}

\section{2 分流比行洪方式在淮河 2003 年与 2007 年大水中的检验}

2003 年与 2007 年汛期,淮河流域遭遇了 1954 年以来的两次流域性大洪水. 由于雨区和降雨时段集中, 雨量大,导致淮河干流、支流水位普遍上涨,河段水位全面超过警戒水位. 两场洪水的行洪参数见表 2 . 假定 在行洪稳定时, 口门处的流速接近河道主槽流速. 采用控制站实测的点最大流速作为行洪口门平均流速, 过 水面积采用行洪区上、下口门中较小的数值. 代人公式(3) 即可得到分流比值.

表 22003 与 2007 年行洪区使用情况

Tab. 2 Applied cases of flood diversion areas of 2003 and 2007

\begin{tabular}{|c|c|c|c|c|c|c|}
\hline \multirow{2}{*}{ 年份 } & \multicolumn{2}{|c|}{ 南润段 } & \multicolumn{2}{|c|}{ 邱家湖 } & \multicolumn{2}{|c|}{ 唐垛湖 } \\
\hline & 开始时间 & 分流比 & 开始时间 & 分流比 & 开始时间 & 分流比 \\
\hline 2003 & - & - & $7-1112: 00$ & 0.11 & $7-616: 00$ & 0.22 \\
\hline 2007 & $7-11 \quad 12: 00$ & 0.1 & $7-1116: 00$ & 0.25 & - & - \\
\hline
\end{tabular}

2003 年与 2007 年的洪水模拟结果见图 2 ( 图中不行蓄洪预报指的是在预报过程中不考虑行蓄洪区的 使用情况,默认行蓄洪区均无进出洪;行蓄洪预报指的是在预报过程中考虑行蓄洪区的使用,进行行蓄洪区 的进出洪计算) 和表 3 , 可以看出经过行洪处理两场洪水的精度均比没有处理有所提高. 对于 2003 年洪水模 拟预报,南照集的预报最高水位误差由 $0.45 \mathrm{~m}$ 降至 $0.37 \mathrm{~m}$, 润河集的最高水位误差由 $0.40 \mathrm{~m}$ 降至 $0.31 \mathrm{~m}$, 汪 集的水位误差由 $0.36 \mathrm{~m}$ 降至了 $0.24 \mathrm{~m}$, 正阳关与鲁台子预报误差分别降至 $0.34 \mathrm{~m}$ 和 $0.31 \mathrm{~m}$. 对于 2007 洪 水,在进行行洪处理时, 南照集、润河集的水位已经达到峰值, 故最大水位误差没有变化,汪集预报误差由 $0.42 \mathrm{~m}$ 降至 $0.37 \mathrm{~m}$, 正阳关由 $0.30 \mathrm{~m}$ 降至 $0.19 \mathrm{~m}$, 鲁台子预报误差降至 $0.16 \mathrm{~m}$. 从两场洪水的流量来看,鲁台 
子站的洪峰相对误差分别由 $-10.7 \%$ 提高到 $-1.6 \%$ 和由 $-6.5 \%$ 提高到 $-1.5 \%$. 确定性系数也有所提高.

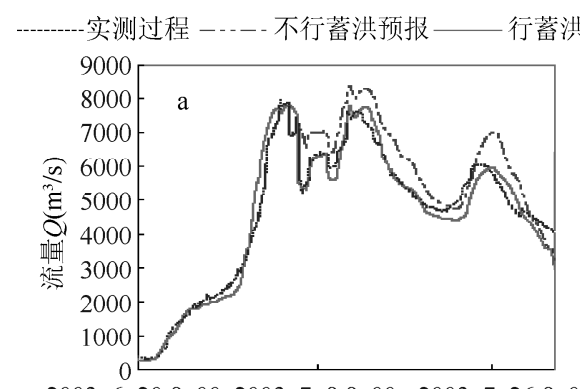

2003-6-20 8:00 2003-7-8 8:00 2003-7-26 8:00

日期
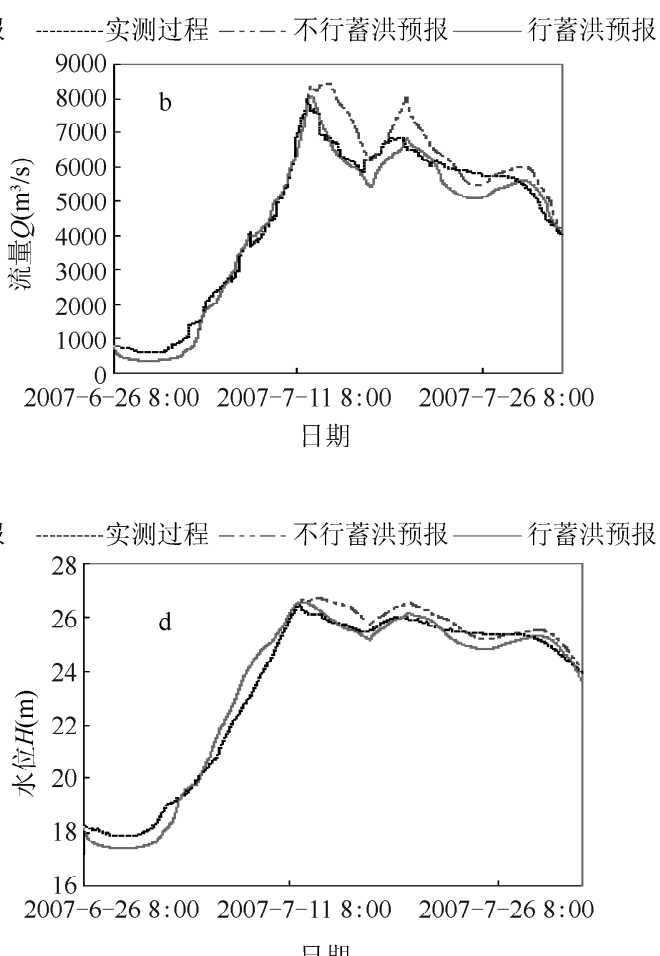

日期

图 2 鲁台子站 (a,b) 和正阳关站 (c,d) 2003 年与 2007 年汛期洪水流量预报过程

Fig. 2 Flood forecast results of Lutaizi station(a,b) and Zhengyangguan station(c,d) in 2003 and 2007

表 3 分流比行洪鲁台子站预报结果

Tab. 3 Flood forecast results of Lutaizi station with using Split ratio method

\begin{tabular}{|c|c|c|c|c|c|c|c|c|}
\hline \multirow[b]{2}{*}{ 年份 } & \multicolumn{4}{|c|}{ 流量预报 } & \multicolumn{4}{|c|}{ 水位预报 } \\
\hline & $\begin{array}{c}\text { 实测峰值 } \\
\left(\mathrm{m}^{3} / \mathrm{s}\right)\end{array}$ & $\begin{array}{c}\text { 预报峰值 } \\
\left(\mathrm{m}^{3} / \mathrm{s}\right)\end{array}$ & $\begin{array}{c}\text { 相对 } \\
\text { 误差(\%) }\end{array}$ & $\begin{array}{l}\text { 确定性 } \\
\text { 系数 }\end{array}$ & $\begin{array}{c}\text { 实测最 } \\
\text { 大水位 } \\
(\mathrm{m})\end{array}$ & $\begin{array}{c}\text { 预报最 } \\
\text { 大水位 } \\
(\mathrm{m})\end{array}$ & $\begin{array}{c}\text { 平均 } \\
\text { 误差 }(\%)\end{array}$ & $\begin{array}{c}\text { 确定性 } \\
\text { 系数 }\end{array}$ \\
\hline 2003 & 7980 & 8831 & -10.7 & 0.877 & 26.51 & 27.20 & 0.69 & 0.865 \\
\hline $2003^{*}$ & 7980 & 8111 & -1.6 & 0.965 & 26.51 & 26.82 & 0.31 & 0.946 \\
\hline 2007 & 7950 & 8466 & -6.5 & 0.892 & 26.00 & 26.52 & 0.52 & 0.863 \\
\hline $2007^{*}$ & 7950 & 8073 & -1.5 & 0.977 & 26.00 & 26.37 & 0.37 & 0.879 \\
\hline
\end{tabular}

*表示考虑行蓄洪的洪水预报.

\section{4 结语}

淮河流域存在行蓄洪区等多种水利工程, 本文基于一维水动力学模型, 合理处理好陟岗分流、大洪水时 支流洪水受干流顶托作用, 概化行蓄洪处理方式, 并考虑了临淮岗枢纽工程对淮河干流洪水波的影响, 建立 了淮河具有行蓄洪区河系洪水预报水力学模型. 通过在淮河洪水预报中的检验, 与水文学预报模型相比, 大 大提高了水位预报精度, 证明了模型的合理性与适用性, 为相对复杂的河系洪水预报问题研究提供了一定 的借鉴. 但鉴于大流域洪水预报的复杂性,仍需要进一步研究: 
（1）行洪区的处理本文使用的是一些基于经验性的方式. 行洪区内洪水演算属于二维水力学范畴,本 文只是用 Muskingum 法概化处理. 研究更适合行洪区处理和洪水演进的方法也是接下来的工作之一.

(2) 无资料地区的产汇流参数是移用淮北王市集小流域产汇流参数. 近 20 年,数字高程模型 (DEM) 和 遥感技术在水文学中得到了迅猛的发展. 如何直接从流域的土壤资料、DEM 技术等 ${ }^{[6,13-15]}$ 直接提取大流域水 文模型的产汇流参数是下一步需要解决的问题.

\section{5 参考文献}

[ 1 ] Maidment DR. Handbook of hydrology. New York: McCraw-Hill, 1992.

[ 2 ] Singh VP. Computer models of watershed hydrology. Littleton, Colorado, USA: Water Resources Publications, 1995.

[ 3 ] 包红军. 基于 EPS 的水文与水力学相结合的洪水预报研究 [学位论文]. 南京: 河海大学,2009.

[ 4 ] Tokar AS, Johnson PA. Rainfall-runoff modeling using artificial neural networks. Journal of Hydrologic Engineering, 1999, 4(3) : 232-239.

[ 5 ] 夏达忠, 张行南. 复杂大流域洪水预报方案通用化构建技术研究模型研究. 水电能源科学, 2009,27(5):40-43.

[6] 包红军,李致家,王莉莉. 具有行蓄洪区的复杂水系实时洪水预报研究. 水力发电学报,2009,28(4):5-12.

[ 7 ] 王船海,李光炽. 实用河网水流计算. 南京: 河海大学出版社,2003.

[ 8 ] 吴时强, 吴修锋,周 辉等. 淮河临淮岗洪水控制工程洪水调度模型研究. 水科学进展,2005,16(2):196-202.

[ 9 ] 吴时强,吴修锋,周 辉等. 淮河临淮岗洪水控制工程洪水调度数学模型应用. 水利水运工程学报, 2009,3:1-7.

[10] Fread DL. Flow routing. In: Maidment DR, ed. Handbook of hydrology. New York: McGraw-Hill, 1992.

[11] Bao HJ, Zhao LN. Hydraulic Model with Roughness coefficient updating method based on Kalman filter for channel flood forecast. Water Science and Engineering, 2011,4(1): 13-23.

[12] 水利部淮委水利科学研究院.淮河临淮岗洪水控制工程深孔闸、浅孔闸、船闸局部整体及断面水工模型模型试验 报告. 蚌埠,2003.

[13] Yao C, Li ZJ, Bao HJ et al. Application of a developed Grid-Xinanjiang model to Chinese watersheds for flood forecasting purpose. Journal of Hydrologic Engineering, 2009,14(9) : 923-934.

[14] 李致家. 水文模型的应用与研究. 南京: 河海大学出版社, 2008 .

[15] Bao HG, Wang LL, Li ZJ et al. Hydrological daily rainfall-runoff simulation with BTOPMC model and comparison with Xin'anjiang model, Water Science and Engineering, 2010,3(2): 121-131. 